\title{
QUANTITATIVE AND QUALITATIVE CRITERIA FOR ASSESSING ENDURANCE IN WOMEN OVER 60 YEARS OF AGE - FINDINGS FROM A PILOT STUDY
}

\author{
JAKUB KORTAS ${ }^{1}$, KATARZYNA PRUSIK ${ }^{2}$, ŁUKASZ BIELAWA ${ }^{1}$, MONIKA WIECH', ZBIGNIEW \\ OSSOWSKI ${ }^{1}$, SEWERYNA KONIECZNA ${ }^{3}$, KRZYSZTOF PRUSIK ${ }^{1}$
}

\author{
${ }^{1}$ Gdansk University of Physical Education and Sport, Faculty of Tourism and Recreation, Department of Health \\ Promotion, Division of Recreation and Professional Tourism \\ ${ }^{2}$ Gdansk University of Physical Education and Sport, Faculty of Tourism and Recreation, Department of Health \\ Promotion, Division of Biomedical Aspects of Health \\ ${ }^{3}$ Medical University of Gdańsk, Faculty of Health Sciences with Subfaculty of Nursing and Institute of \\ Maritime and Tropical Medicine, Department of Social Medicine, Division of History and Philosophy of \\ Medical Sciences
}

Mailing address: Jakub Kortas, Gdansk University of Physical Education and Sport, 1 Kazimierz Górski Street, 80-336 Gdańsk, tel.: +48 58 5547323, fax: +48 58 5547324, e-mail: jakub.kortas@awfis.gda.pl

\begin{abstract}
Introduction. If it is to be effective, health training needs to be monitored based on regular and periodic assessment. The norms that have been proposed for standardised endurance tests for the 60-plus age group, particularly for women, still require evaluation. In light of the above, we have undertaken to design quantitative and qualitative criteria for assessing the level of endurance. Such criteria are urgently needed by persons working with this age group. Material and methods. We developed a quantitative and qualitative system for evaluating endurance based on Zatsiorky's model, and we verified it in a group of 90 women aged over 60 years. We analysed data measured directly during a 2-km walk test. Results. We developed a set of quantitative and qualitative criteria for assessing endurance in women aged over 60 years based on the results of a 2-km walk test, measured on a scale ranging from 24:18 to 15:52 min:s. Conclusion. The pilot study has proven that a scale based on Zatsiorsky's model can be an effective tool for assessing endurance in women aged over 60 years. We can thus recommend that it be widely used in practice. It is important to compare these results with the norms for the group in question and to establish comprehensive norms that could be useful for persons who organise physical activity for older adults.
\end{abstract}

Key words: endurance, the elderly, health promotion

\section{Introduction}

In order to design an effective training programme, one needs to consider both the available research findings and practical issues to do with the cultural and social factors impacting a given group [1-3]. Training programmes should be designed based on the following three stages: 1) determining the elements of the programme, 2) devising the structure of the programme, and 3) monitoring the effectiveness of the programme regularly. In the first stage, information is collected regarding pertinent theories and methodologies, research findings, as well as the experiences of the best trainers in a given country and the solutions applied in training programmes abroad. The second stage consists in developing the programme in such a way that it can be used by the trainers and that they can give feedback on their experience in implementing the programme. It is worth emphasising that the programme should comprise both short- and long-term goals. The last stage involves continuously evaluating the programme and monitoring its effectiveness by implementing it in various groups and environments [4-6].
If a training programme targeted at a particular group is to be designed, certain measurements should be made first. In the case of training programmes for persons of average health with no contraindications to moderate-intensity exercise, programmes should be developed based on an assessment of aerobic capacity, which is indicative of the capacity of the body to adapt to long-lasting effort [7]. Other biological and fitnessrelated factors are used merely to modify the programme. Aerobic capacity needs to be measured under conditions that are safe for the participants of physical activity classes; the tests which are performed the most often are walk tests (including those carried out using treadmills) [8-14], stair-climbing tests [15-17], the Eurofit test [18, 19], and the Senior Fitness Test [20, 21]. The need to measure physical fitness has been underscored by persons working in nursing homes, who have stated that its measurement should be one of the elements of general health assessments [22-27].

The main method used in this study, that is the $2-\mathrm{km}$ walk test component of the Eurofit test battery for adults, has been verified and validated in several studies involving different 
groups of subjects [28-34]. Researchers who have used walking tests have analysed walking velocity, the appropriateness of the tests for subjects with particular health conditions, maximal effort capacity, and the functional state of the subjects [813]. However, there remains a need to continue to examine the population of women aged over 60 years and the results of the research concerning this group.

We believe that, for this purpose, it is necessary to design a scale for assessing the results of the $2-\mathrm{km}$ walk test among persons aged over 60, an instrument which is currently unavailable. In addressing this gap, we have formulated the following research questions:

1) How should an endurance assessment scale be developed based on Zatsiorsky's model?

2) Can a scale based on Zatsiorsky's model be an effective tool for assessing endurance in women aged over 60 years?

In order to create a precise assessment scale, we carried out a three-stage research process in a group of 90 women who were over 60 years of age. In the first stage of our research, we recorded the walking time of the research participants. In the second stage, we designed a scale for assessing endurance using the walk test based on Zatsiorsky's mathematical model, which was to be verified empirically. In the final stage, the participants took part in a 12-week health training programme in Nordic walking, and measurements were performed before and after the subjects completed the training cycle. The results achieved by the participants were interpreted using the scale that had been designed, which made it possible to verify it.

The verification we carried out was aimed at adjusting the scale in such a way that it could be sensitive to changes in the research participants' level of endurance, since significant changes are typically not found in older adults who undergo healthrelated training, and this may lead to the false conclusion that the training was ineffective. In the age group in question, the training can be considered effective when a person's endurance level does not deteriorate with time and remains at the initial level [35].

Table 1. Number of subjects in particular age categories

\begin{tabular}{|c|c|c|}
\hline \multirow{2}{*}{ Age category } & \multicolumn{2}{|c|}{ All groups } \\
\cline { 2 - 3 } & $\mathrm{N}$ & $\%$ \\
\hline $60-65$ years & 27 & 30 \\
\hline $66-70$ years & 36 & 40 \\
\hline 71 years and more & 27 & 30 \\
\hline
\end{tabular}

\section{Material and methods}

\section{Research participants}

The study involved 90 women aged 60-78 years who lived in the cities of Gdańsk and Sopot in Poland (tab. 1). The subjects were selected to take part in the study based on a medical certificate from their family doctor confirming that there were contraindications to their participation in the health training programme and the blood pressure measured on the day of the walk test.

\section{Walk test procedure}

The method of measuring endurance used in the study was the $2-\mathrm{km}$ walk test. Its original name is the UKK Walk Test. The acronym UKK is based on the initials of Urho Kaleva Kekkonen, who was the president of Finland in the years 1956-1982. The test was designed by Finnish researchers working at the Institute for Health Promotion [18, 21]. It consists in walking at a brisk and steady pace. In this particular study, the test was performed on a running track in a sports hall $\left(18^{\circ} \mathrm{C}\right)$ at the Gdansk University of Physical Education and Sport in order to exclude variables related to weather conditions and the walking surface. The participants completed ten 200-m loops, and they made turns in such a way that they did not need to slow down. Before the test, the participants did a warm-up consisting in performing dynamic exercise which prepared them for doing brisk walking. The participants wore sports clothing and shoes. During the test, the subjects were encouraged to walk as fast as possible, but they were not allowed to run.

\section{Training programme}

The research participants took part in outdoor Nordic walking sessions. The training consisted in continuous walking. The overall structure of the training programme was based on systematic increases in training intensity, expressed as the distance covered in each of the training sessions (tab. 2). This distance gradually increased from $2 \mathrm{~km} 210 \mathrm{~m}$ to $6 \mathrm{~km} 10 \mathrm{~m}$. The training sessions were attended by $80.52 \%$ of the subjects on average.

\section{Design of the scale for assessing endurance in women aged 60-78 years}

The endurance level of the group of women aged 60-78 years was assessed qualitatively and quantitatively based on Zatsiorsky's model [36]. The scale was developed by normalising the variables using the mean and standard deviation.

The analysis included data measured directly during the $2-\mathrm{km}$ walk test. In accordance with the mathematical model for scale design, the distribution of the data was examined first. This was done by generating a histogram and testing the data

Table 2. Structure of the training programme undergone by the participants

\begin{tabular}{|c|c|c|c|c|c|c|c|c|c|c|c|c|c|}
\hline Week & 1 & 2 & 3 & 4 & 5 & 6 & 7 & 8 & 9 & 10 & 11 & 12 & \\
\hline \multirow{3}{*}{ Pretest } & $\mathrm{T}$ & $\mathrm{T}$ & C & C & C & C & C & $C$ & C & C & $C$ & C & \multirow{3}{*}{ Pretest } \\
\hline & $\mathrm{T}$ & $\mathrm{T}$ & $C$ & $C$ & $C$ & C & C & $C$ & C & C & $C$ & C & \\
\hline & $\mathrm{T}$ & $\mathrm{T}$ & C & $C$ & C & C & C & $C$ & C & C & C & C & \\
\hline Training intensity (\%) & 30 & 30 & 40 & 40 & 40 & 50 & 50 & 50 & 60 & 60 & 70 & 70 & \\
\hline
\end{tabular}

${ }^{\star} \mathrm{T}=$ Nordic walking technique training; $\mathrm{C}=$ continuous Nordic walking. 
for normality of distribution using the Shapiro-Wilk test. The graphic representation of the results confirmed by normality testing showed that the data were normally distributed $(\mathrm{p}=$ 0.07). The data tended to be skewed to the right. Many of the observations were located in the lowest interval, which made it possible to precisely determine the interval of the maximal results achieved by the participants. The mean and median were found to have similar values (tab. 3). This would indicate that the mean represented the average value accurately, and thus one of the main requirements for designing a reliable scale was met.

Taking into account the results of the analysis of data distribution discussed above, we used a normalised $\mathrm{T}$ scale. The scale was based on 100 points, with 50 points indicating the average value and a 10-point interval corresponding with one standard deviation. The following formula was used when designing the T scale:

$$
T=50+\frac{10(x-X)}{S D}
$$

where:

$x$ - measurement result,

$X$ - mean for all the measurement results,

$S D$ - standard deviation for all the measurement results.

Constructed in this way, the scale is proportional: the number of points on the scale increases proportionally to the increase in the values recorded in the measurement. Values beyond the scale range should be considered outliers and should be analysed individually; such analyses could lead to the conclusion that these values are extreme values or the result of a measurement error.

\section{Adjustment of the scale}

In addition to the above, in order to make the scale more readable and sensitive, we made adjustments based on the analysis of the results and in particular the spread of the data. We introduced the following modifications: we converted the scale from a 100-point to a 10-point scale, and the intervals were reduced to half of the standard deviation, which made the scale more sensitive.

The scale was constructed as follows: the mean score (X) was the middle point of the scale, the intervals were equal to half of the standard deviation $( \pm 0.5 \mathrm{SD})$, and the results which differed from the mean by more than three SDs were considered to be due to a measurement error, which is a standard assumption made when constructing such scales.

Based on our previous experience, we decided to reduce the intervals proportionally for low results. In walking tests, one should also consider the fact that it is rather unlikely that the results will increase by more than 2.5 standard deviations. That is why we divided the interval between 1 and 1.5 SD proportionally; in our opinion, the results which fall into this part of the scale can be seen as indicative of a high level of endurance.

\section{Quantitative and qualitative criteria for assessing endurance}

So as to prepare the scale for practical use, we developed a graphic version of the scale (fig. 1) that can be recommended for monitoring the health training process in women aged 6078 years. The results achieved by a given person should be classified according to left-closed and right-open intervals, apart from the first point category, where both intervals are open. An analogous rule should be followed in qualitative assessment. Points 1-3 designate a low level of endurance, points 4-7 indicate an average level, and points 8-10 denote a high level.

\section{Results}

\section{Verification of the scale for assessing endurance in women aged $60-78$ years}

The empirical verification of the scale in a group of 90 women who underwent health training confirmed that it had been constructed in an appropriate way, which is proven by the

Table 3. Statistics concerning the results of the 2-km walk test

\begin{tabular}{cccccccc}
\hline & $\mathbf{X}$ & Me & Min & Max & SD & V\% & Skewness \\
\hline Test duration [min:s] & $19: 02$ & $18: 54$ & $15: 25$ & $25: 25$ & $2: 07$ & $11 \%$ & 0.44 \\
\hline
\end{tabular}

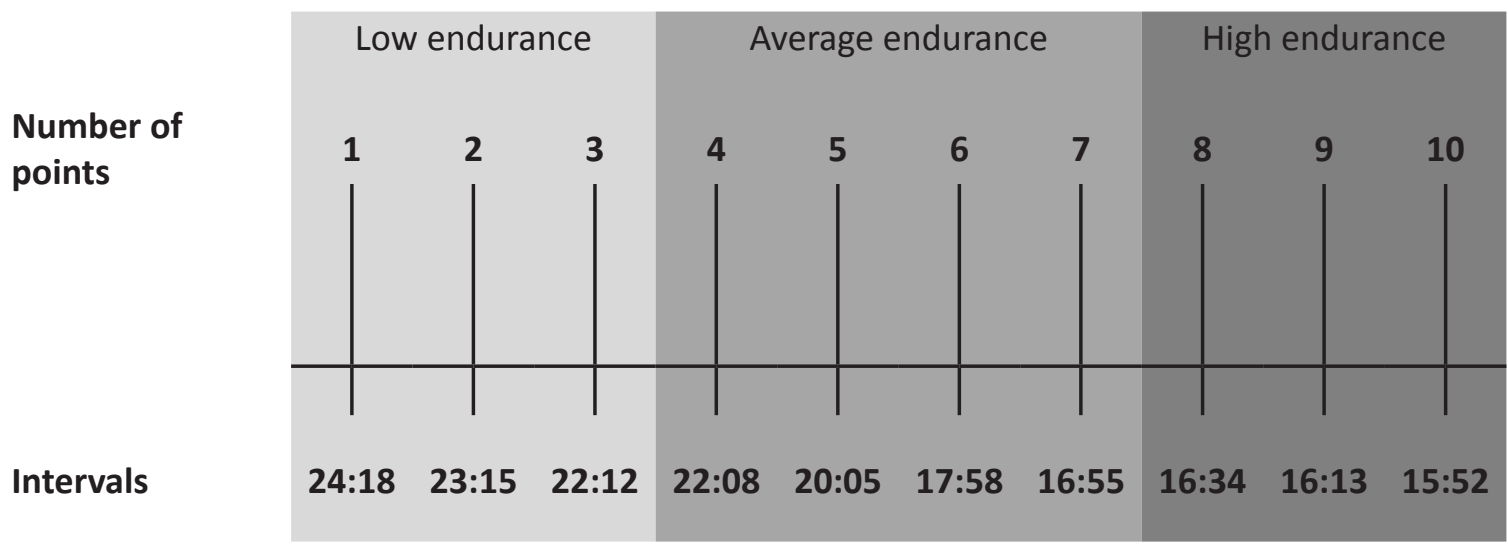

Figure 1. Assessment scale for the 2-km walk test [min:s] 
percentage distribution of the results and corresponding numbers of points. The point categories located in the middle of the scale ( 4 to 7 points) had the highest number of results $(55.6 \%$ in the first test and $52.2 \%$ in the second one). It is also worth emphasising that the mean quantitative results achieved by the participants differed between the pretest (PRE) and posttest (POST) (fig. 2). These differences were confirmed to be statistically significant at $\mathrm{p}<0.05$.

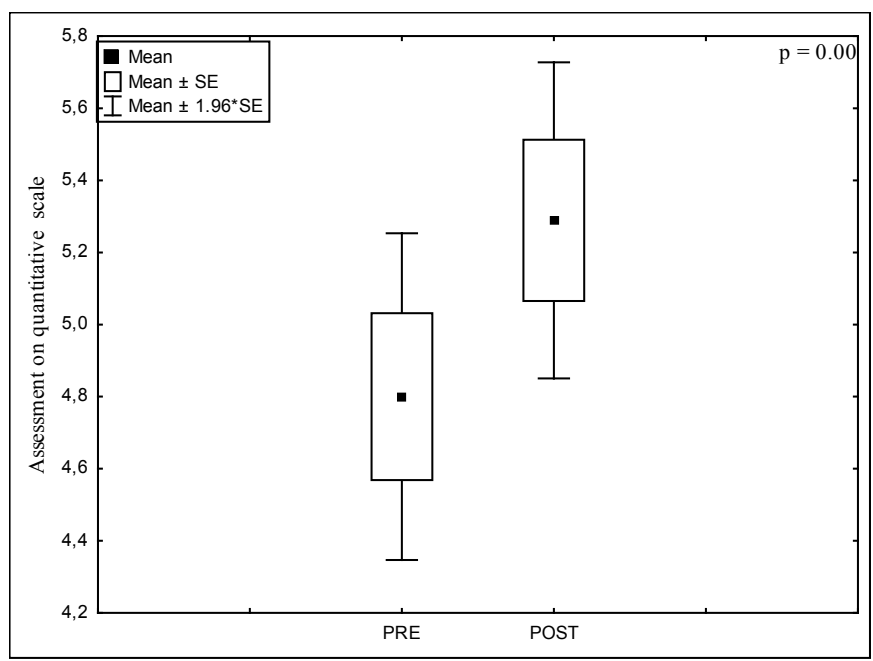

${ }^{*} \mathrm{SE}=$ standard error.

Figure 2. Changes in the quantitative scale: the results obtained for the older adult women $(\mathrm{n}=90)$ before and after the 12-week training cycle

The scale presented in the current paper is a sensitive instrument for assessing the level of endurance in women aged 60-78 years, since it reflects the normal distribution of scores in the population. The scale can be used to identify extreme and outlying results.

When we analysed the distribution of the results on the qualitative scale consisting of three categories (a low, average, and high level of endurance), we found that the measurement results were distributed in a uniform way. Based on the results of the $2-\mathrm{km}$ walk test, more than $50 \%$ of the women were classified as persons with an average level of endurance. The fact that persons with an average level of endurance were the most numerous means that the scale reflects the situation in the population of women aged $60-78$ years.

\section{Discussion}

The current study has focused on the qualitative and quantitative assessment of endurance, based on the results of the UKK 2-km walk test.

A study which is comparable in scope was conducted in Japan [37]. In that study, a 12-minute walking test was used, and the mean distance covered was recorded; this distance was 1,142 $\mathrm{m}( \pm 77)$ in the pretest and $1,266 \mathrm{~m}( \pm 89)$ in the posttest. The confidence interval of the change in the results was defined as $92.5 \mathrm{~m}$ to $154.4 \mathrm{~m}$, that is an average of $123 \mathrm{~m}$. The results obtained in our study which are presented in this article can thus be seen as corresponding with the literature on the subject and reproducible in other measurement conditions.
Currently, the trend that can be observed in research concerning endurance in older adults is that short endurance tests are being conducted. The test that is most commonly mentioned in the literature is the 6-minute walk test (the corridor walk test). This test has several unquestionable advantages. It is short and easy to perform; moreover, reliable scales which have been described in detail are available to those who decide to apply it. In addition, it is safe and adequate for persons with a low level of physical activity, including those living in nursing homes, or persons who have had a cardiac episode. Notwithstanding the many advantages of this test, we would like to emphasise that further research is needed to design reliable tests for measuring specific endurance. This study has proven that the $2-\mathrm{km}$ walk test can be useful, in particular for the age group in question.

According to the findings of research previously conducted by ourselves and by other authors, despite a high level of interest in taking part in regular physical activity classes on enrolment, after this initial period of enthusiasm, as many as $50 \%$ of older adult women discontinue training. This tendency is not related to the women's health issues or the excessive intensity of the training, but to the habits these women have acquired in their youth, when they did not develop the habit of performing regular physical activity. For this reason, the participants of such experiments tend to be women who have practised competitive or recreational sports in the past, as well as those who have been professionally and/or socially active their entire lives. It is thus worth emphasising that the results presented in the current article most likely do not accurately reflect the results that would be recorded for the average woman aged 60-78 years, since, based on the literature, only $7 \%$ of women this age deliberately took part in physical activity in their youth [38], whereas this figure was as high as $51.1 \%$ in the group of subjects in this study.

With the current demographic situation, the assessment of endurance performed in this study would apply to our future society, considering the fact that efforts are being made to increase the participation of persons of all ages in systematic physical activity over the entire course of their lives. To sum up, our findings are representative of a group which can be regarded as an elite among women aged $60-78$ years in the current population.

Appropriately designed scales for the assessment of the level of physical fitness make it possible to assess several aspects of the health of older adults [39]. Some examples include bone mineral density, medicine use, or the proper functioning of the respiratory system [40-42]. Moreover, methods of functional capacity assessment can be used in medical practice [43].

\section{Conclusion}

Although there is a large body of research assessing the level of physical activity, the scales which are most commonly designed are often based on questionnaires [44, 45], despite the fact that physical fitness tests are considered to be more effective in assessing health parameters than questionnaires [46, 47]. Physical fitness tests are most often performed among persons living in nursing homes. In this article we have proposed a scale for assessing the endurance and physical capacity of women using a fitness test, which has been verified on women who live independently. 


\section{Literature}

1. Gazmararian J.A., Elon L., Newsome K., Schild L., Jacobson K.L. (2013). A randomized prospective trial of a worksite intervention program to increase physical activity. American Journal of Health Promotion 28(1), 32-40.

2. Shinkai S., Yoshida H., Taniguchi Y., Murayama H., Nishi M., Amano H. et al. (2016). Public health approach to preventing frailty in the community and its effect on healthy aging in Japan. Geriatrics $\mathcal{E}$ Gerontology International 16(1 Suppl.), 87-97.

3. King A.C., Rejeski W.J., Buchner D.M. (1998). Physical activity interventions targeting older adults. A critical review and recommendations. American Journal of Preventive Medicine 15(4), 316-33.

4. Bondarchuk A.P. (1988). Constructing a training system. Track Technique 102(1), 3254-3259.

5. Corlett J.T.U. (1973). A system model of physical training and athletic performance. Brock University. Canada: Academic Press.

6. Plowman S.A., Smith D.L. (2013). Exercise physiology for health fitness and performance. Philadelphia: Wolters Kluwer Health.

7. Kuński H., Janiszewski M. (1999). Medicine of physical activity for educators. Łódź: Wydawnictwo Uniwersytetu Łódzkiego. [in Polish]

8. Bohannon R.W., Wang Y.C., Gershon R.C. (2015). Two-minute walk test performance by adults 18 to 85 years: normative values, reliability, and responsiveness. Archives of Physical Medicine and Rehabilitation 96(3), 472-477.

9. Chung P.K., Zhao Y., Liu J.D., Quach B. (2016). Functional fitness norms for community-dwelling older adults in Hong Kong. Archives of Gerontology and Geriatrics 65, 54-62.

10. Graham J.E., Fisher S.R., Berges I.M., Kuo Y.F., Ostir G.V. (2010). Walking speed threshold for classifying walking independence in hospitalized older adults. Physical Therapy 90(11), 1591-7.

11. Graham J.E., Ostir G.V., Kuo Y.F., Fisher S.R., Ottenbacher K.J. (2008). Relationship between test methodology and mean velocity in timed walk tests: A review. Archives of Physical Medicine and Rehabilitation 89(5), 865-72.

12. Kavanagh T., Shephard R.J. (1976). Maximum exercise tests on "postcoronary" patients. Journal of Applied Physiology 40(4), 611-8.

13. Ko V., Naylor J.M., Harris I.A., Crosbie J., Yeo A.E. (2013). The six-minute walk test is an excellent predictor of functional ambulation after total knee arthroplasty. BMC Musculoskeletal Disorders 14, 145.

14. Hall J., Grant J., Blake D., Taylor G., Garbutt G. (2004). Cardiorespiratory responses to aquatic treadmill walking in patients with rheumatoid arthritis. Physiotherapy Research International 9(2), 59-73.

15. Brown-Rowat A., Jeans M.E. (1990). Professional and executive women: Health and lifestyle characteristics. Health Care for Women International 11(2), 133-49.

16. Clemons J., Harrison M. (2008). Validity and reliability of a new stair sprinting test of explosive power. The Journal of Strength \& Conditioning Research 22(5), 1578-83.

17. Laursen P. (1997). The impact of aging on cognitive functions. An 11 year follow-up study of four age cohorts. Acta Neurologica Scandinavica 172, 7-86.

18. Oja P., Laukkanen R., Pasanen M., Tyry T., Vuori I. (1991). A 2-km walking test for assessing the cardiorespiratory fit- ness of healthy adults. International Journal of Sports Medicine 12(4), 356-62.

19. Apor P. (1992). Eurofit - program of the Committee of the European Council for the Advancement of Athletics. Orvosi Hetilap 133(13), 817. [in Hungarian]

20. Rikli R.E., Jones C.J. (2013). Development and validation of criterion-referenced clinically relevant fitness standards for maintaining physical independence in later years. Gerontologist 53(2), 255-67.

21. Suni J.H., Oja P., Laukkanen R.T., Miilunpalo S.I., Pasanen M.E., Vuori I.M. et al. (1996). Health-related fitness test battery for adults: Aspects of reliability. Archives of Physical Medicine and Rehabilitation 77(4), 399-405.

22. Rockwood K., Song X., MacKnight C., Bergman H., Hogan D., McDowel I. et al. (2005). A global clinical measure of fitness and frailty in elderly people. Canadian Medical Association Journal 173(5), 489-395.

23. Halaweh H., Willen C., Grimby-Ekman A., Svantesson U. (2015). Physical activity and health-related quality of life among community dwelling elderly. Journal of Clinical Medicine Research 7(11), 845-52.

24. Bastone Ade C., Ferriolli E., Teixeira C.P., Dias J.M., Dias R.C. (2015). Aerobic fitness and habitual physical activity in frail and nonfrail community-dwelling elderly. Journal of Physical Activity \& Health 12(9), 1304-11.

25. Kamegaya T., Araki Y., Kigure H. (2014). Twelve-week physical and leisure activity programme improved cognitive function in community-dwelling elderly subjects: A randomized controlled trial. Psychogeriatrics 14(1), 47-54.

26. Lee S., Yuki A., Nishita Y., Tange C., Kim H., Kozakai R. et al. (2016). Research relationship between light-intensity physical activity and cognitive function in a community-dwelling elderly population: An 8-year longitudinal study. Journal of the American Geriatrics Society 61(3), 452-3.

27. Martin K., Jarvis L.A., Beale B. (1997). Healthy lifestyle check: A computerized health screening program. Computering Nursing 15(2), 77-81.

28. Gulias-Gonzalez R., Sanchez-Lopez M., Olivas-Bravo A., Solera-Martinez M., Martinez-Vizcaino V. (2014). Physical fitness in Spanish schoolchildren aged 6-12 years: Reference values of the battery EUROFIT and associated cardiovascular risk. Journal of School Health 84(10), 625-35.

29. Heimer S., Misigoj-Durakovic M., Ruzic L., Matkovic B., Prskalo I., Beri S. et al. (2004). Fitness level of adult economically active population in the Republic of Croatia estimated by EUROFIT system. Collegium Antropologicum 28(1), 223-33.

30. Skowronski W., Horvat M., Nocera J., Roswal G., Croce R. (2009). Eurofit special: European fitness battery score variation among individuals with intellectual disabilities. Adapted Physical Activity Quarterly 26(1), 54-67.

31. Tsigilis N., Douda H., Tokmakidis S.P. (2002). Test-retest reliability of the Eurofit test battery administered to university students. Perceptual and Motor Skills 95(3 Suppl.), 1295-300.

32. Vancampfort D., Probst M., Sweers K., Maurissen K., Knapen J., Willems J.B. et al. (2012). Eurofit test battery in patients with schizophrenia or schizoaffective disorder: Reliability and clinical correlates. European Psychiatry 27(6), 416-21.

33. Vancampfort D., Sienaert P., Wyckaert S., De Hert M., Stubbs B., Rosenbaum S. et al. (2015). Test-retest reliability, feasibility and clinical correlates of the Eurofit test battery 
in people with bipolar disorder. Psychiatry Research 228(3), 620-5.

34. Yurdalan S.U., Kondu S., Malkoc M. (2007). Assessment of health-related fitness in the patients with end-stage renal disease on hemodialysis: Using Eurofit Test Battery. Renal Failure 29(8), 955-60.

35. Steffen T.M., Hacker T.A., Mollinger L. (2002). Age-and gender-related test performance in community-dwelling elderly people: Six-Minute Walk Test, Berg Balance Scale, Timed Up \& Go Test, and gait speeds. Physical Therapy 82(2), 128-137.

36. Zatsiorsky V. (1979). Fundamentals of sports metrology. Moscow: Fizkultura i Sport. [in Russian]

37. Takeshima N., Islam M.M., Rogers M.E., Rogers N.L., Sengoku N., Koizumi D. et al. (2013). Effects of Nordic walking compared to conventional walking and band-based resistance exercise on fitness in older adults. Journal of Sports Science $\mathcal{E}$ Medicine 12(3), 422-432.

38. Marchewka A., Jungiewicz M. (2008). Physical activity in early years of life versus quality of life in old age. Gerontologia Polska 16(2), 127-130. [in Polish]

39. Siordia C. (2012). Alternative scoring for Physical Activity Scale for the Elderly (PASE). Maturitas 72(4), 379-82.

40. Granger C.L., Parry S.M., Denehy L. (2015). The self-reported Physical Activity Scale for the Elderly (PASE) is a valid and clinically applicable measure in lung cancer. Supportive Care in Cancer 23(11), 3211-8.

41. Hosseini S.R., Zabihi E., Ghadimi R. (2015). Relationship between physical activity and medicine use among the ol- der people in Amirkola, Babol, Iran (2011-2012). Caspian Journal of Social Medicine 1(1), 11-16.

42. Monemi Amiri A., Hosseini S.R., Rahmaninia F., Nooreddini H., Bijani A. (2015). Relationship between bone mineral density and physical activity level in the elderly. Annals of Applied Sport Science 3(2), 23-32.

43. Wiktor K., Drozdzowska B., Czekajło A., Hebel R. (2010). Selected methods of evaluating functional capabilities in clinical practice. Annales Academiae Medicae Silesiensis 64, 76-81. [in Polish]

44. Ismail N., Hairi F., Choo W.Y., Hairi N.N., Peramalah D., Bulgiba A. (2015). The Physical Activity Scale for the Elderly (PASE): Validity and reliability among community-dwelling older adults in Malaysia. Asia-Pacific Journal of Public Health 27(8 Suppl.), 62-72.

45. Jachimowicz V., Kostka T. (2009). Assessment of selfefficacy in the residents of older people homes. Gerontologia Polska 17(1), 23-31. [in Polish]

46. Logan S.L., Gottlieb B.H., Maitland S.B., Meegan D., Spriet L.L. (2013). The Physical Activity Scale for the Elderly (PASE) questionnaire: Does it predict physical health? International Journal of Environmental Research and Public Health 10(9), 3967-86.

47. Ewald B., McEvoy M., Attia J. (2010). Pedometer counts superior to physical activity scale for identifying health markers in older adults. British Journal of Sports Medicine 44(10), 756-61.

Submitted: June 10, 2016

Accepted: September 15, 2016 